\title{
A DIGNIDADE DA PESSOA: \\ UM VALOR FORA DO COMÉRCIO E ÍNSITO AO TRABALHO
}

\author{
Ricardo Tadeu Marques da Fonseca*
}

\section{INTRODUÇÃO}

O Direito do Trabalho surge, historicamente, voltado para uma discussão filosófica e política concernente ao princípio da igualdade e esta é a discussão que nos move no presente trabalho.

A atual retomada das concepções liberais, pretensamente hegemônicas, traz à baila, novamente, esta discussão que, em verdade, nunca saiu de pauta. Talvez o malogro da experiência soviética tenha propiciado uma retomada das idéias neoliberais, que vêm colocando em xeque o Estado Social e apresentando a chamada economia de mercado como contraponto a qualquer forma

* Doutorando do Programa de Pós-Graduação em Direito da UFPR e Procurador do Ministério Público do Trabalho.
SUMÁRIO: 1. Introdução. 2. A História do Direito do Trabalho. 3. O Direito do Trabalho, um fenômeno pós-moderno.

de intervenção do Estado na sociedade, na economia ou nas relações entre capital e trabalho.

Remanesce, porém, a evidência de que a maior parte dos grupos sociais está à margem das conquistas do Estado de Direito, e isso mais se acentua nos países periféricos que, por sinal, também estão à margem das benesses econômicas do mercado.

A relação de dominação entre os homens e o estabelecimento da lei, como mecanismo de legitimação do poder e de sua limitação, constitui a base da afirmação das igualdades.

O processo de evolução das relações humanas desenvolveu-se, ao longo dos séculos, de forma muito gradual, mas, nos dois últimos, assumiu matizes intensos e significativos.

As conquistas da cidadania participativa e da dignidade da pessoa, então, caracterizam 
a base da relação entre a lei e o cidadão. O próprio conceito de cidadania, aliás, também se submete às concepções históricas acerca da igualdade.

$\mathrm{Na}$ Antigüidade, vigorava a regra da dominação, eis que povos melhor organizados econômica e militarmente subjugavam os demais. A economia, dessa forma, lastreava-se no trabalho escravo. Domênico de $\mathrm{Masi}^{1}$ afirma que para cada cidadão ateniense havia oito escravos, em média. Logo, a noção de igualdade inicialmente desenvolvida por Platão e Aristóteles ${ }^{2}$ tinha como pressuposto a concepção da igualdade entre os iguais.

Embora a proposta aristotélica sobre justiça igualitária tenha constituído o cerne da afirmação das conquistas iluministas, não superava o evidente desequilíbrio social que vigorava como sustentáculo da democracia ateniense. Igualdade entre homens adultos e cidadãos atenienses, que excluía todos os outros membros daquela sociedade.

O mérito da filosofia platônica e aristotélica reside, no entanto, no fato de que se passou a planejar de forma racional a construção da pólis, utilizando-se, para tanto, da observação das leis naturais que poderiam e deveriam ser compreendidas e aplicadas ao convívio humano. Caminhar de acordo com essas leis implicaria estar em harmonia com a natureza e se habilitar para o sucesso e a felicidade. Todos que alcançassem esses misteres atingiriam uma posição de destaque social

1 MASI, Domênico de. A Emoção e a Regra. Rio de Janeiro: José Olímpio, 1999.

2 GENEVOIS, Margarida. Direitos Humanos na História. Enciclopédia Virtual de Direitos Humanos. Disponível em: <http://www.dhnet.org.br/direitos/ anthist/margarid.htm>. Acesso em: 15/05/2003. por seus méritos, os quais justificavam o "insucesso" da maioria.

A igualdade, destarte, consistiria em atribuir a cada um o que lhe fosse devido por mérito.

Durante a Idade Média, a necessidade de proteção em face das invasões dos bárbaros estruturou a sociedade européia em torno do poder militar e do domínio territorial. A força se impunha mais uma vez. Os elos de dominação, porém, agora pautados pelo poder temporal da Igreja, sedimentavam-se como o dever de ajuda mútua entre senhores e servos, nobres e clero, nobreza e rei. Somente com a Carta Magna de 1215 traçam-se alguns limites à dominação real em face dos senhores feudais.

Santo Agostinho e São Tomás de Aquino ${ }^{3}$ retomam a teoria do Direito Natural sistematizado a partir de Aristóteles, acrescentando o ingrediente da divindade onipotente que se materializava no poder da Igreja. Mas a idéia de que a pobreza e a riqueza eram atributos naturais concedidos por Deus conformava, ainda, a organização social e legitimava o poder político do rei.

Essa realidade forjou-se no curso de dezenas de séculos, vindo a transformar-se bruscamente com a expansão mercantilista da Europa e com a Revolução Industrial dos séculos XVI a XVIII, que consolidaram economicamente a burguesia. Essa classe social, visando à conquista do poder político, passou a questionar as bases ideológicas do antigo regime, dado que já lograra solapar os alicerces econômicos da sociedade feudal, rural.

\footnotetext{
3 GENEVOIS, ob.cit.
} 
Os movimentos políticos que se sucedem visam afirmar uma sociedade igualitária, na qual as ações do Estado se reduziriam; em que o indivíduo seria o centro de emanação dos direitos, cabendo ao governo assegurar a liberdade individual e limitar o seu poder de acordo com essa mesma liberdade. Surgem, assim, os direitos fundamentais de primeira geração. As liberdades individuais, o direito à vida, à segurança, à igualdade de todos perante a lei, o direito de propriedade e o direito de ir e vir.

O Direito Civil estrutura-se sob inspiração das leis e instituições burguesas. Um direito patrimonialista, patriarcal e que instrumentalizava, por intermédio do contrato, o trânsito patrimonial.

O absenteísmo estatal, todavia, finda por implicar, ao longo do século XIX, profunda cisão social, originando a busca de uma igualdade concreta que, segundo Marx, seria de índole econômica, a qual só se poderia implantar com a abolição da propriedade privada dos bens de produção. Segundo outros, com a incorporação ao ordenamento jurídico de regras e princípios que, embora preservando a propriedade privada dos bens de produção, propiciassem o equilíbrio das forças sociais.

Emergem, desse modo, os direitos fundamentais de segunda geração, direitos de índole coletiva e que dependem de atuação direta do Estado. São os direitos à saúde, educação, moradia, trabalho, lazer e os trabalhistas.

Ao longo do século XX, mais intensa se tornou a disputa ideológica acerca da igualdade, pois, enquanto no Leste Europeu firmavam-se os Estados socialistas, no
Ocidente cresciam duas tendências referentes ao Estado Intervencionista.

A primeira tipificava-se nos Estados corporativistas nazifascistas e, a segunda, nos Estados intervencionistas democráticos de Direito. Ao cabo da Segunda Guerra, eliminam-se os primeiros e se fortalecem as democracias sociais, que desenvolvem uma ampla rede de proteção social, assegurando direitos mínimos gerais pela ação estatal, no sentido de equilibrar as desigualdades substanciais.

No Terceiro Mundo, retoma-se o viez autoritário do Estado Intervencionista em sucessivos golpes militares, por meio dos quais ditaduras armadas subtraem os direitos civis e políticos, intervindo na economia sob o pretexto da busca de progresso econômico e do combate à "ameaça socialista".

Ao passo em que se firmam as democracias e se adota o Estado de Bem-Estar Social como alternativa ao modelo autoritário ocidental com a retomada do poder pelo povo e com o sucessivo desmonte das ditaduras militares, instala-se uma crise aguda no modelo de referência intervencionista democrática, a partir da Revolução Tecnológica dos anos 80 e da derrocada dos Estados de inspiração ideológica marxista.

Ressurge a busca do Estado Liberal, bem refletida na teoria de John Ralws, ${ }^{4}$ que defende uma igualdade de oportunidades em que todos são considerados a partir de um patamar de organização social ideal, devendo o Estado garantir oportunidades equilibradas para todos. Trata-se da retomada do pacto social nos moldes traçados por Rousseau e

4 RAWLS, John. Uma Teoria da Justiça. São Paulo: Martins Fontes, 1997. 
Kant. O Consenso de Washington também pugna pela redução do intervencionismo econômico estatal para que se eliminem os custos do processo econômico, devendo o mercado reger naturalmente as relações deste jaez.

O surgimento dos blocos econômicos e da organização transglobal da economia põe em xeque até mesmo a idéia de soberania territorial. A onda de flexibilização da lei assume grandes proporções na área trabalhista (os direitos sociais são considerados "custos econômicos"). Simultaneamente, em contrapartida, nota-se no Direito Civil e nas relações de consumo um movimento em sentido oposto: tornam-se essas relações fortemente publicistas, rompendo-se os elos patrimonialistas privados. Diversas ações afirmativas são empreendidas com estímulo de organismos internacionais, no sentido de se dedicar às minorias segregadas ou inferiorizadas socialmente uma gama de medidas compensatórias, visando recuperar as perdas sociais que lhes foram impostas.

A contradição histórica entre as ações liberais de precarização da rede de proteção social e as medidas de preservação dos direitos fundamentais sociais pela constitucionalização desses direitos sintetiza a perquirição deste trabalho.

\section{A HISTÓRIA DO DIREITO DO TRABALHO}

Para tanto, convém verificar as razões históricas que levaram à criação do Direito do Trabalho e que suscitaram a sua atual crise. Conforme já afirmado, trata-se de um direito de índole suplementar às liberdades individuais, aos direitos fundamentais do ser humano; na expressão de Paulo Bonavides, ${ }^{5}$ um direito fundamental de segunda geração, sem que isso implique qualquer hierarquia relacional entre eles e os de primeira geração.

Ao longo do século XIX e, mais acentuadamente, na primeira metade do século XX, tornou-se um direito universal, disciplinador das relações entre capital e trabalho, a partir da percepção de que o Estado deveria equilibrar essas forças, indicando os caminhos da política econômica, bem como das ações relacionais entre a força humana de trabalho, os bens de produção e seus detentores.

O cerne do Direito do Trabalho consiste na idéia de proteção jurídica daqueles que oferecem apenas sua força no processo produtivo. Adquirem patrimônio jurídico que os equipara, socialmente, aos que detêm o patrimônio econômico. De outra parte, esta normatização viabiliza a pacificação das tensões naturais que caracterizam a oposição de interesses existentes.

Assim é que a partir da Encíclica Rerum Novarum, da Constituição Mexicana de 1917, da Constituição de Weimar de 1919 e da criação da OIT, também ocorrida em 1919, pelo Tratado de Versalhes, a universalização do Direito do Trabalho apresenta-se como uma medida de regulação do mercado internacional para fixar patamares mínimos inerentes à dignidade humana, cujo valor está fora do comércio.

Essa medida, porém, encontra-se em xeque e enfrenta profunda crise originada na derrocada dos países socialistas, conforme

5 BONAVIDES, Paulo. Curso de Direito Constitucional. 13.ed., $2^{\mathrm{a}}$ tiragem. São Paulo: Malheiros Editores, 2003, p. 564/569. 
já observado, e na mudança do processo produtivo de feições globais. A globalização econômica tem forjado uma tentativa de hegemonia ideológica neoliberal que impõe valores de primazia economicista e acarreta severo quadro de exclusão humana e social.

Segundo o professor Abili Lázaro Castro de Lima, ${ }^{6}$ que estuda os aspectos da exclusão da grande maioria da população no mundo globalizado, a globalização econômica fortaleceu a influência política das empresas transnacionais que, em razão do processo econômico transcontinental, articulado pela produção caracterizada pela automação industrial e pela transmissão imediata just in time de informações e decisões, subjugam as fronteiras nacionais e a própria soberania dos Estados. Preconizam, por isso mesmo, a adoção da política neoliberal de redução do Estado a patamares mínimos.

\section{Citando Boaventura de Sousa Santos,} ressalta o autor que o processo de globalização não é apenas uma retomada dos preceitos liberais do contrato social de Rosseau, trata-se, isto sim, de um novo contratualismo social que elimina direitos antes tidos por inalienáveis e, por outro lado, impede tanto a retomada desses direitos, para quem os possuíra, quanto o acesso daqueles que jamais os alcançaram. No dizer de Sousa Santos:

A predominância dos processos de exclusão apresenta-se sob duas formas, na aparência, contraditórias: o pós-contratualismo e o précontratualismo. O pós-contratualismo é processo pelo qual grupos e interesses sociais até agora incluídos no contrato social são dele excluídos sem qualquer perspectiva de regresso.

6 LIMA, Abili Lázaro Castro de. Globalização Econômica, Política e Direito - análise das Mazelas Causadas no Plano Político-Jurídico. Porto Alegre: Sérgio Antônio Fabris Editor, 2002.
Os direitos da cidadania, antes considerados inalienáveis, são-lhes confiscados e, sem estes, os excluídos passam da condição de cidadãos à condição de servos. O pré-contratualismo consiste no bloqueamento do acesso à cidadania por parte dos grupos sociais que anteriormente se consideravam candidatos à cidadania $\mathrm{e}$ tinham a expectativa fundada de a ela aceder. ${ }^{7}$

Gilberto Dupas, inspirando-se nos trabalhos de Rogers, afirma que a exclusão pode ocorrer em diversos aspectos da vida social: culturais, econômicos, sociais, políticos e psicológicos. Desta forma, lembra-nos que Rogers codifica as exclusões em sete graus, a seguir enumerados:

a) exclusão do mercado de trabalho (desemprego a longo prazo); b) exclusão do trabalho regular (parcial e precário); c) exclusão do acesso a moradias decentes e a serviços comunitários; d) exclusão do acesso a bens e serviços (inclusive públicos); e) exclusão dentro do mercado de trabalho (para ele, existe uma 'dualização do processo de trabalho', ou seja, há empregos ruins, de acesso relativamente fácil - que além de precários não geram renda suficiente para garantir um padrão de vida mínimo - e há empregos bons, mas de difícil acesso, que geram níveis de renda e de segurança aceitáveis; em geral, a segmentação acontece em termos de raça, sexo, nacionalidade); f) exclusão da possibilidade de garantir a sobrevivência; $g$ ) exclusão do acesso à terra; h) exclusão em relação à segurança, em três dimensões: insegurança física, insegurança em relação à sobrevivência (o risco de perder a possibilidade de garanti-la) e insegurança em relação à proteção contra contingências; i) exclusão dos direitos humanos. ${ }^{8}$

7 SANTOS, Boaventura de Sousa. Reinventar a democracia. In: OLIVEIRA, Francisco de e PAOLI, Maria Célia (Org.). Os sentidos da democracia: políticas do dissenso e hegemonia global. Petrópolis: Vozes, 1999, p. 95-96 apud LIMA, ob. cit., p. 271.

8 DUPAS, Gilberto. Economia global e exclusão social: pobreza, emprego, Estado e futuro do capitalismo. Apud LIMA, ob. cit., p. 274. 
Introduzindo as idéias de John Gray, ressalta o professor Abili que as medidas de Margareth Thatcher, pioneira na implantação das idéias neoliberais, trouxeram um sórdido quadro de exclusões. Segundo Gray, uma em cada cinco famílias na Grã-Bretanha, sem contar os pensionistas, não tem uma pessoa sequer trabalhando. Tal situação só é encontrada nos Estados Unidos.

Outro aspecto denunciado por Gray é a extinção das moradias de propriedade dos conselhos municipais, grande bandeira eleitoral do thatcherismo, que, nos anos 90, voltou-se contra os conservadores, uma vez que o Estado passou a despender vultosas quantias com auxílio-habitação (1996-97: 11 bilhões de libras esterlinas - 1,5\% do PIB da $U K$ - o décuplo do custo da década anterior). Com isso, aumentaram de forma acentuada os gastos com a previdência social. Constata-se, portanto, que o neoliberalismo prega a privatização, o enxugamento do Estado, mas gera, contraditoriamente, ônus sociais que devem ser suportados pelo próprio Estado.

Sublinha, ainda, John Gray ${ }^{9}$ que os países europeus que não adotaram o neoliberalismo não passaram pela mesma catástrofe social, cuja ocorrência só se deu em proporções tão avassaladoras nos Estados Unidos. Tal evidência pode ser espelhada no índice de prisões efetuadas que, na Inglaterra, cresceu assustadoramente, no que foi superado apenas pelos Estados Unidos (entre 1992 e 1993 a população carcerária inglesa cresceu perto de um terço - mais de 50 mil prisioneiros). Prossegue Gray reportando o fato de que a

9 GRAY, John. "Falso amanhecer: os equívocos do capitalismo global" apud DE LIMA, op. cit., p. 275-276. concentração de renda nunca foi tão exacerbada na Grã-Bretanha. Em 1984-1985 a quinta parte da população detinha $43 \%$ da renda líquida, a mais alta concentração do pós-guerra.

Para abordar o desemprego, um dos maiores fatores de exclusão da globalização, traz o professor Abili as lições de Marilena Chauí. ${ }^{10}$ Segundo Chauí, o desemprego passou a ser estrutural, eis que a lógica do capitalismo contemporâneo reside na exclusão da maioria pela automação da produção e pela alta rotatividade de mão-de-obra que progressivamente se desqualifica em face do ritmo veloz das mudanças tecnológicas. Perdem poder os sindicatos e aumenta a pobreza absoluta (na América Latina há 196 milhões abaixo da linha de pobreza).

Eric. J. Hobsbawm, ${ }^{11}$ a seu turno, vislumbra um sério abalo nos laços sociais de solidariedade familiar e empresarial. As empresas têm incrementado a automação do processo de produção e de serviços, fazendo do emprego moeda de troca nas negociações sindicais. Isso tem levado a uma exacerbação do individualismo em detrimento dos vínculos de lealdade social.

Acrescentamos, nós, aos argumentos de Hobsbawm, as idéias defendidas por Richard Sennet, ${ }^{12}$ na obra "A corrosão do caráter". Sennet demonstra que os vínculos de caráter romperam-se em razão da imediatidade das expectativas profissionais e dos retornos em face dos investimentos do capital.

${ }^{10}$ CHAUÍ, Marilena. "Ideologia neoliberal e universidade" apud DE LIMA, op. cit., p. 278-279.

${ }^{11}$ HOBSBAWM, Eric. J. O novo século. Apud DE LIMA, op. cit., p. 281-282

${ }^{12}$ SENNET, Richard. A corrosão do caráter. 5. ed. Rio de Janeiro: Editora Record, 2001. 
O futuro parece bastante assustador. O professor Abili L. C. de Lima alude a um relato de Hans-Peter Martin e Harald Schumann acerca de uma reunião realizada em setembro de 1995 num luxuoso hotel de São Francisco, nos EUA, acerca da Fundação Gorbachev e seu futuro. $\mathrm{O}$ encontro reuniu diversos líderes mundiais da época, como George Bush e Maragaret Thatcher, além de membros de grandes corporações internacionais que, ao debaterem os rumos que o mundo viria a tomar no século XXI, concluíram que a sociedade do futuro será a "sociedade 20 por 80", ou seja, somente haverá trabalho para $20 \%$ da população economicamente ativa do mundo, a qual será suficiente para produzir todos os bens e prestar todos os serviços de que a sociedade mundial necessitará. Os outros 4/5 da população restante, serão mantidos "satisfeitos" com uma mistura de entretenimento e alimento, consagrado no termo tittytainment, de autoria de Zbigniew Brzezinski, assessor de Segurança Nacional do governo do presidente americano Jimmy Carter. Uma espécie de retomada da política romana do "pão e circo", que produz um resultado bastante conhecido e pouco desejado.

A globalização econômica estabeleceu uma nova divisão internacional do trabalho em que o processo de produção é realizado em vários países, onde seus custos com trabalhadores, carga tributária, garantias sociais sejam menores. Isso provoca o agravamento do dumping social, com crescente desemprego, queda dos valores nominais dos salários e perdas dos direitos sociais.

De um lado, a ausência, ou quase ausência, de coesão entre os agentes sociais impede que os trabalhadores unam-se entre si por intermédio das entidades de classe, enfraquecendo-as, por conseqüência. Por outro lado, a falta de coesão na sociedade desmancha os laços de solidariedade entre os agentes sociais: os trabalhadores não mais se identificam com os não-trabalhadores, os quais ou se conformam ou se isolam da cultura social existente; o mesmo ocorre entre os detentores do capital, os agentes econômicos e políticos com os miseráveis e excluídos da sociedade, nada fazendo, assim, para melhorar ou reverter o quadro da pobreza. Daí a dificuldade dos sindicatos de agregar interesses, mobilizar apoio político, implicando a perda de seu poder de pressão contra os empregadores, de articulação política na esfera pública, postulando reivindicações da classe trabalhadora (uma espécie de fraqueza política crônica), bem como garantindo os direitos outrora conquistados.

Em síntese, os sindicatos e suas centrais trabalhistas estão perdendo aos poucos suas capacidades para realizar as finalidades para as quais foram constituídos; o desemprego avançando drástica e rapidamente, os laços solidários da sociedade sendo quebrados, tudo leva a uma situação social bastante propícia a erupções violentas e intermináveis de grupos sociais contra estrangeiros, raças, "tribos". Atílio Borón afirma que "neste marco, como é muito evidente, se evaporam quase por completo a figura do cidadão e da democracia, e as perspectivas de uma cidadania participativa e autogovernada e de um capitalismo democrático, pelo menos na periferia, se tornam cada vez mais problemáticas".13

O professor Abili explica que "a exclusão social gerada pelo desemprego produz uma

\footnotetext{
13 BORÓN op. citi., apud DE LIMA, op. cit., p. 301.
} 
decomposição dos valores humanísticos e sociais, deixando os indivíduos desamparados e jogados à própria sorte"14 (comprometendo seriamente sua dignidade), os quais não podem nem sequer recorrer ao Estado para reduzir suas mazelas, pois este encontra-se fragilizado em face de sua miniaturização, bandeira das políticas neoliberais. Hoje, o status de cidadão não mais se refere ao homem provido de direitos, mas sim àquele que possui acesso ao consumo.

No Brasil, o modo feudal de produção perdurou até as primeiras décadas do século $\mathrm{XX}$, quando se inicia o processo de industrialização. A edição da Lei Áurea foi um marco para a dissolução do regime escravocrata, cujas raízes se alastraram por quatro séculos da nossa história e delinearam de forma muito intensa as condutas trabalhistas no País, condutas estas que ainda perduram em grande medida, eis que denúncias constantes de trabalho escravo comprovam-se verdadeiras por todo o País até o presente. A inobservância do Direito do Trabalho, sob o pretexto dos altos custos dos encargos sociais, tem levado $60 \%$ dos trabalhadores à informalidade, mesmo quando a prestação de serviço preenche as características do contrato de emprego.

As representações empresariais insistiram, nas últimas duas décadas, na redução dos direitos laborais, defendendo a bandeira da flexibilização ou da desregulamentação, a qual foi acenada com grande alarde como solução para o desemprego estrutural, característico da mudança do processo econômico no período. Várias medidas foram

\footnotetext{
${ }^{14}$ DE LIMA, op. cit., p. 301
}

adotadas nessa direção, e a economia brasileira, no entanto, não reagiu: o desemprego aumentou progressivamente, atingindo um patamar de $12,8 \%$ da força economicamente ativa e, nas grandes metrópoles, 18 a $20 \%$.

Segundo Márcio Pochmann, ${ }^{15}$ porém, essa derrocada econômica foi causada por uma política externa servil e por uma abertura desordenada do mercado interno. Por essa razão, são inócuas as medidas desregulamentadoras e precarizantes da relação de emprego.

A Consolidação das Leis do Trabalho completou sessenta anos em 2003 e, certamente, fazem-se necessárias revisões. Muito se discute hoje no Brasil acerca de quais caminhos tomar. O governo procura estabelecer canais de conversação com a sociedade, eis que o fracasso histórico das medidas puramente neoliberais já se patenteou tanto aqui como na Europa.

As origens autoritárias do modelo sindical e da própria forma pela qual foi editada a CLT têm sido utilizadas como motivo de eiva que afetaria todo o modelo, levando muitos a defender a adoção da negociação coletiva como substituta da lei. Tal argumento levanta-se entre componentes dos dois pólos centrais da negociação.

Realmente, Getúlio Vargas "amarrou" o desenvolvimento das relações laborais no País ao adotar o modelo corporativista preconizado na Carta del Lavoro, vinculando a ação sindical ao controle rigoroso do Estado, que se institucionalizou pela Carta Sindical. Tratava-se, como se sabe, de uma autorização para criação e funcionamento

15 POCHMANN, Márcio. A Década dos Mitos O Novo Modelo Econômico e a Crise do Trabalho no Brasil. São Paulo: Editora Contexto, 2001, p. 39/50. 
dos sindicatos dada exclusivamente pelo Estado, o qual distribuía as organizações profissionais e econômicas de acordo com critérios de conveniência e controle político, facilmente administrados pela forma da unicidade sindical, do imposto sindical e do poder normativo da Justiça do Trabalho. Os entes jurídicos, artificialmente criados para corporificar esses institutos, eram as categorias profissionais e econômicas delimitadas pelo Estado naquela mesma Carta Sindical.

Assinale-se que as discussões em torno da reforma trabalhista não têm enfatizado a revisão do conceito de categoria, ou mesmo de sua implicação como única forma de vinculação sindical. Talvez este seja o cerne do modelo corporativista, a partir do qual deve-se, realmente, repensar o modo de organização sindical brasileiro.

Com efeito, a principal conseqüência da organização getulista do Direito do Trabalho foi o refreamento do desenvolvimento sindical no País, visto que as categorias mais fortes e organizadas já haviam conquistado uma série de direitos legais, os quais foram consolidados no diploma trabalhista e estendidos, genericamente, aos trabalhadores urbanos.

Por outro lado, porém, estancou-se a ação sindical, na medida em que, desde a implantação do modelo, em 1937, até a Constituição de 1988, notou-se que as categorias melhor organizadas enfraqueceram-se e que as mais frágeis não romperam os grilhões da dependência. Instituíram-se, a partir de 1988, com o aparente afrouxamento da ingerência estatal, milhares de "sindicatos de fachada", cuja representatividade é evidentemente questionável. Além do mais, o movimento efetivamente atuante reluta em se despojar do imposto sindical e da unicidade, considerando as dificuldades por que passa a organização dos trabalhadores em todo o mundo, em face da automação e da globalização.

O discurso da flexibilização e da desregulamentação, iniciado há duas décadas, persiste e vem pautando as discussões da reforma trabalhista, sendo quase consensual a adoção da autonomia privada coletiva como princípio jurídico nuclear, eis que já adotado na Constituição para a redução dos salários, a negociação sobre a jornada de trabalho e os turnos ininterruptos de revezamento.

\section{O DIREITO DO TRABALHO, UM FENÔMENO PÓS-MODERNO}

Esta qualidade do Direito do Trabalho é muito bem defendida por Jorge Pinheiro Castelo. ${ }^{16}$ Demonstra que o racionalismo liberal é o dado ideológico que norteou as promessas da modernidade. A ideologia burguesa liberal pregava a liberdade econômica como valor supremo, a partir do qual todos os outros se consolidariam.

O Direito do Trabalho veio a lume, justamente, porque tais promessas não se cumpriram e se evidenciou que a relação entre capital e trabalho revelava o primeiro ponto de ruptura com a chamada liberdade econômica racional, iluminista.

A implantação do direito do trabalho, como já dito, fez-se ao longo do século XX e chegou ao auge após a Segunda Guerra Mundial. Nas últimas duas décadas, porém,

\footnotetext{
${ }^{16}$ CASTELO, Jorge Pinheiro. O Direito Material e Processual do Trabalho e a Pós-Modernidade - A CLT, o CDC e as repercussões do Novo Código Civil. São Paulo: LTr Editora, 2003.
} 
os valores liberais da modernidade vêm sendo reafirmados em favor da liberdade econômica de mercado e em detrimento do intervencionismo estatal ou, melhor dizendo, do Estado de Bem-Estar Social.

Um dos principais ideólogos do neoliberalismo nas relações de trabalho no Brasil é José Pastore, cujas idéias sintetizam a ofensiva ideológica que vigeu no período. Afirma que o custo dos encargos sociais em nosso país remonta a $103,49 \%$ do valor do salário pago ao trabalhador, o que inviabilizaria as contratações. Propõe, então, que sejam flexibilizados e desregulamentados os direitos trabalhistas para que se possam negociar férias, décimo-terceiro salário, aviso prévio, reduzindo, assim, o valor dos encargos sociais em prol da empregabilidade. ${ }^{17}$

Os principais ideólogos do neoliberalismo já vinham se opondo ao Estado de Bem-Estar Social desde o final da Segunda Guerra Mundial. Frederich Hayeck e Milton Friedman estabeleceram as bases ideológicas do que veio a ser o Consenso de Washington. Pugnavam pelo fim de qualquer intervencionismo estatal na economia ou na sociedade por meio das privatizações, admitindo o controle inflacionário, mas sob a égide do mercado, cujas flutuações harmonizariam naturalmente as relações sociais. Suas idéias naquele momento não vingaram, eis que o chamado New Deal de inspiração keynesiana possibilitou um desenvolvimento econômico

${ }^{17}$ PASTORE, José. Muitos direitos e poucos empregos. O Jornal da tarde. 25 de mai. de 1994. Disponível em: <http://www.josepastore.com.br/artigos/ emprego/003.htm>. Acesso em: 2 de mar. 2004; Legislação trabalhista é mais cara. ANotícia. Joinville, 2 de dez. 2001. Disponível em: <http://an.uol.com.br/ 2001/dez/02/0pai.htm>. Acesso em: 3 de mar. 2004. sem par nos anos 1950, 1960, o que também ocorreu na Europa com o crescimento da social democracia.

Buscavam, os detratores da expansão social-democrata, o retorno aos velhos dogmas liberais dos séculos XVIII e XIX e passaram a ser bem-sucedidos a partir dos anos 1970, com a crise do petróleo e com a queda da ameaça socialista durante os anos 1980 e 1990. Suas idéias assumiram a primazia hegemônica no processo de globalização. O Direito do Trabalho vem sendo acusado por partidários dessa corrente de pensamento como algo anacrônico, superado, quando as bases ideológicas dos críticos dos direitos sociais, elas sim, remontam aos primórdios do Iluminismo Liberal e já se encontram sabidamente esvaziadas pela inexorável evidência histórica.

Marcio Pochmann ${ }^{18}$ demonstra que desde 1990, quando se iniciou o processo de liberalização da economia e privatização como desmonte estatal, bem como de flexibilização e desregulamentação da legislação trabalhista, os principais sintomas de desequilíbrio econômico no Brasil só se agravaram com o aumento de concentração de riqueza, desemprego e "financeirização da riqueza". No que concerne às medidas de precarização e desregulamentação trabalhista, reafirma sua ineficácia, pois o índice de desemprego não se reduziu ao longo dos anos 1990 vindo, ao contrário, a aumentar progressivamente, o que ocorreu em caráter simultâneo com a perda de capacidade aquisitiva do consumidor. Alude, outrossim,

18 POCHMANN, Márcio. A década dos mitos. São Paulo: Editora Contexto, 2001. 
à incorreção metodológica do índice apontado por Pastore, eis que padece de imprecisão conceitual, "confundindo cotização patronal (encargo social ou custo não salarial) com rendimento do trabalho (custo salarial ou salário bruto) e, por conseqüência, produzindo invariavelmente engodos técnicos". 19

A afirmação concernente ao custo da folha é seriamente questionável, uma vez que a remuneração do trabalho jamais pode ser considerada como encargo, uma vez que sem trabalho o capital não se reproduz; logo, trata-se de investimento imprescindível à própria manutenção do sistema. Por outro lado, o índice indicado por Pastore é incorreto sob o ponto de vista jurídico, visto que se compõe de elementos que dizem respeito à contraprestação do trabalho propriamente dita. As férias, o descanso semanal remunerado e os repousos em geral são por ele computados como custo adicional, mas o valor recebido pelos trabalhadores quando em repouso destina-se à preservação de sua saúde física, mental e à necessidade de convívio social e político, valores que são ínsitos à dignidade humana, inestimáveis sob o ponto de vista econômico e cuja inobservância implica elevado custo social que se revela em acidente do trabalho e afastamentos por motivos de saúde que acarretam elevadíssimos custos à Previdência Social e, portanto, a toda sociedade. Contrariamente ao método adotado pelo professor paulista, há que se afastar do cômputo do índice mencionado o aviso prévio, já que só é devido quando da despedida imotivada, inocorrendo nas hipóteses de pedido de demissão,

\footnotetext{
${ }^{19}$ Ibid., p. 108.
}

aposentadoria, acidente do trabalho com invalidez, morte do trabalhador e mesmo quando o contrato se mantém.

A crise da empregabilidade não deve ser atribuída aos valores pagos aos trabalhadores. Como se viu, a capacidade de consumo é imprescindível à reprodução do capital e o custo social da informalidade é, sem dúvida, muito mais intenso que qualquer atribuição legal que se possa exigir concernentemente ao emprego. Trata-se de atributo inerente à função social da livre iniciativa e da propriedade dos bens de produção, princípios constitucionais basilares.

Faz-se necessária, portanto, a verificação das razões que insuflaram a crise de valores que hoje impera, conduzida pela primazia dos valores econômicos sobre todos os outros. As conquistas obtidas na modernidade, no sentido de consolidar e assegurar os direitos individuais, os Estados Nacionais e as liberdades públicas, não foram suficientemente hábeis a se manter por si mesmas, tampouco os direitos sociais lograram consolidá-las na maior parte dos países e estes são tidos como pesados ônus à produção, sendo objeto de séria cogitação a sua eliminação.

Analisando os fatores da crise da modernidade, explica Boaventura de Sousa Santos $^{20}$ que o paradigma sociocultural da modernidade pode ser descrito por intermédio de dois pilares filosóficos: a) regulação, constituído pelos princípios do Estado (Hobbes), do mercado (Locke e Adam Smith) e da comunidade (Rousseau); e

${ }^{20}$ SANTOS, Boaventura de Sousa. A crítica da razão indolente - contra o desperdício da experiência. 3. ed. São Paulo: Cortez Editora, 2001, p. 47-54. 
b) emancipação, caracterizado pelas três lógicas da racionalidade definidas por Weber - racionalidade estético-expressiva das artes e da literatura, racionalidade cognitivo-instrumental da ciência e da tecnologia e racionalidade moral-prática da ética e do Direito.

Diagnosticando os aspectos que denotam as razões da crise liberal, afirma que há um forte desequilíbrio entre estes pilares e entre os elementos que os compõem. O pilar da regulação incorporou o da emancipação, desequilibrando as relações de forças. O Estado foi absorvido pelo mercado, ficando relegada a plano inferior a vertente concernente às relações entre Estado e comunidade. No que concerne ao pilar da emancipação, o cientificismo e o legalismo positivista sobrepujaram o estético-expressivo.

Desse modo, os interesses mercantis conduziram à racionalização do processo econômico, maximizando os valores do mercado em detrimento dos valores comunitários e a própria ciência viu-se atada por preceitos epistemológicos inflexíveis, positivistas, que toldaram o Direito e sufocaram a criação estético-expressiva.

Aponta, assim, como solução epistemológica: i) o incremento dos princípios da comunidade (no pilar da regulação) e da racionalidade estético-expressiva (no pilar da emancipação) que, segundo Santos, são as representações que merecem maior atenção, preconizando, deste modo, a exploração das potencialidades dessas vertentes; ii) deve-se, outrossim, incrementar o pilar da emancipação em relação ao da regulação, estimulando-se medidas de longo prazo em prol da solidariedade global; iii) deve-se procurar eliminar a distinção entre o sujeito e o objeto, incorporando-se à ciência o conhecimento do senso comum, das crenças, dos valores, pois inexiste hierarquia entre conhecimento científico e os demais; iv) deve-se, também, romper com a separação natureza e cultura, todas as ciências serão concebidas como ciências sociais; v) com isso, a ciência assumirá outros campos de percepção, superando os padrões ocidentais racionais; vi) faz-se mister, ainda, superar a generalidade de conceitos pretensamente totalizantes, conduzindo-se a pesquisa com olhar atento e cauteloso para com estes novos campos de emanação de cultura; vii) finalmente, deve-se propiciar a fusão das ciências naturais e das ciências sociais revalorizando as humanidades presentes na racionalidade estético-expressiva. ${ }^{21}$

Esse prognóstico detalhado e perspicaz pode se respaldar na própria materialização dos direitos sociais. Sua implantação fez-se exatamente quando se constatou que o Estado deveria abandonar a posição "olímpica", imparcial, pretensamente garantidora da igualdade de todos perante a lei. Desceu do pedestal e passou a ministrar regras que tomaram partido em nome de grupos sociais inferiorizados, compensando-os com um sistema legal capaz de outorgar força jurídica emancipatória em face do poder econômico.

É conveniente insistir que as críticas à implantação dos direitos sociais nada têm de contemporâneas, tampouco representam pensamento de vanguarda, revelando-se extremamente apegadas a conceitos superados quanto ao trabalho humano. Remontam às bases liberais do século XVIII, cujo insucesso

\footnotetext{
${ }^{21}$ SANTOS, Ob. Cit., p. 74-94.
} 
se faz notório e cuja adoção sequer é cogitada nos países do capitalismo central.

Outro grave equívoco metodológico é o de se invocar condutas inerentes a países da Common Law que não guardam quaisquer similitude cultural e histórica com o Brasil que sempre se pautou pela Civil Law. Não se pode romper com uma tradição cultural milenar por decreto.

Outra contradição que se evidencia e vem sendo apontada pelos críticos do neoliberalismo é a ênfase persistente no sentido de se atribuir direitos aos consumidores e se enfocar a cidadania pelo prisma do consumo, ou seja, só é cidadão aquele que tem poder de consumo. Ao mesmo tempo, e contraditoriamente, excluem-se do mercado de trabalho hordas crescentes que, em nome do downsizing empresarial, perdem a capacidade de consumo.

Enquanto os detratores do Direito do Trabalho pugnam pela contratualidade liberal, com a substituição da lei pela autonomia privada coletiva, a classe dominante autoriza e estimula o direito do consumidor. O Código de Defesa do Consumidor brasileiro exsurge justamente no contexto de precarização trabalhista dos anos 1990.

Comentando este "fetiche" pelo consumo, Viviane Forrester ${ }^{22}$ exorta-nos a refletir sobre esta contradição: “ 'O cliente é soberano, princípio sagrado': quem ousaria infringilo?" E prossegue:

Mas, então, por que essa pauperização metódica, organizada, que chamam racional, e até necessária, até mesmo promissora, e que vai se

${ }^{22}$ FORRESTER, Viviane. O horror econômico. Trad: Álvaro Lorencini, 7. a reimp. São Paulo: Editora da Universidade Estadual Paulista, 1997, p. 126-127. agravando? Por que cortar, quase com raiva, das fileiras dos consumidores potenciais dezenas de milhares que, por sua vez, parecem representar as 'galinhas dos ovos de ouro' das 'forças vivas da nação', essas campeãs no jogo das 'criações de riquezas', mas criadoras de tanta pobreza? A economia de mercado teima em serrar o galho sobre o qual pretende estar apoiada? Ela sabota a si mesma a golpes de 'planos sociais', 'reestruturações', flexibilização dos salários, deflação competitiva e outros projetos frenéticos visando abolir as medidas que ainda permitem aos mais desfavorecidos consumir um pouco que seja? Será por masoquismo?

Lembra-nos Jorge Pinheiro Castelo ${ }^{23}$ que o Código do Consumidor nada mais é do que a CLT de "fraque", querendo, com isso, dizer que a estrutura axiológica do Direito do Consumidor é exatamente a mesma do Direito do Trabalho. Os princípios da proteção, o princípio da irrenunciabilidade, o princípio da norma/condição mais favorável, o princípio da razoabilidade, o da boa-fé e o da responsabilidade objetiva compõem o Direito do Consumidor inspirado que foi na idéia pós-moderna de compensação jurídica em face das defasagens sociais.

No mesmo passo evoluiu o Direito Civil. É fato notório que o Código Civil brasileiro agasalha princípios emancipatórios que o repersonalizam, despatrimonializando-o, em favor da dignidade da pessoa. A função social do contrato, o princípio da boa-fé objetiva, os direitos da personalidade, os princípios da paridade contratual e do poder familiar, partilhado entre homens e mulheres, traduzem esta função emancipatória do direito que foi importada pelos demais ramos, sem dúvida, do Direito Laboral.

\footnotetext{
${ }^{23}$ CASTELO, J. P. de. Ob. Cit., p. 226.
} 
É muito difundida a idéia segundo a qual o processo e a forma atuais da globalização seriam irreversíveis. Isso também tem a ver com a força com a qual o fenômeno se revela e instala em todos os lugares e em todas as esferas da vida, levando a pensar que não há alternativas para o presente estado de coisas.

No entanto, essa visão repetitiva do mundo confunde o que já foi realizado com as

\section{REFERÊNCIAS}

BONAVIDES, Paulo. Curso de Direito Constitucional. 13. ed., $2^{a}$ tiragem. São Paulo: Malheiros Editores, 2003.

CASTELO, Jorge Pinheiro. O Direito Materiale Processual do Trabalho e a Pós-ModernidadeA CLT, o CDC e as repercussões do Novo Código Civil. São Paulo: LTr Editora, 2003.

FORRESTER, Viviane. O horror econômico. Trad: Álvaro Lorencini, $7^{\mathrm{a}}$ reimp. São Paulo: Editora da Universidade Estadual Paulista, 1997.

GENEVOIS, Margarida. Direitos Humanos na História. Enciclopédia Virtual de Direitos Humanos. Disponível em: $<$ http://www.dhnet.org.br/direitos/anthist/ margarid.htm>. Acesso em: 15/05/2003.

LIMA, Abili Lázaro Castro de. Globalização Econômica, Política e Direito - análise das Mazelas Causadas no Plano Político-Jurídico. Porto Alegre: Sérgio Antônio Fabris Editor, 2002. MASI, Domênico de. A Emoção e a Regra. Rio de Janeiro: José Olímpio, 1999.

24 SANTOS, Milton. Por uma outra globalização: do pensamento único à consciência universal. 10. ed. Record: Rio de Janeiro, 2003, p. 160. perspectivas de realização. Para exorcizar esse risco, devemos considerar que o mundo é formado não apenas pelo que já existe (aqui, ali, em toda parte), mas pelo que pode efetivamente existir (aqui, ali, em toda parte). O mundo datado de hoje deve ser enxergado como o que na verdade ele nos traz, isto é, um conjunto presente de possibilidades reais, concretas, todas factíveis sob determinadas condições. ${ }^{24}$

PASTORE, José. Muitos direitos e poucos empregos. O Jornal da tarde. 25 de mai. de 1994. Disponível em : <http://www.josepastore.com.br/ artigos/emprego/003.htm> . Acesso em: 02 de mar. 2004; Legislação trabalhista é mais cara. ANotícia. Joinville, 02 de dez. 2001. Disponível em: <http://an.uol.com.br/2001/dez/02/0pai.htm>. Acesso em: 03 de mar. 2004.

POCHMANN, Márcio. A Década dos Mitos - O Novo Modelo Econômico e a Crise do Trabalho no Brasil. São Paulo: Editora Contexto, 2001.

RAWLS, John. Uma Teoria da Justiça. São Paulo: Martins Fontes, 1997.

SANTOS, Boaventura de Sousa. A crítica da razão indolente - contra o desperdício da experiência. 3. ed. São Paulo: Cortez Editora, 2001.

SANTOS, Milton. Por uma outra globalização: do pensamento único à consciência universal. 10. ed. Rio de Janeiro: Record, 2003.

SENNET, Richard. A corrosão do caráter. 5 . ed. Rio de Janeiro: Editora Record, 2001. 